\title{
CJAR
}

Canadian Journal of Action Research

Volume 21, Issue 2, 2021, pages 4-24

\section{ARE GROUNDED THEORY AND ACTION RESEARCH COMPATIBLE? CONSIDERATIONS FOR METHODOLOGICAL TRIANGULATION}

\author{
Anna Azulai \\ MacEwan University
}

\begin{abstract}
This article explores the prospects of combining Grounded Theory (GT) and Action Research (AR) methodologies to spark further methodological discussion. GT and AR methodologies are sometimes used together in the same study without a discussion of their methodological compatibility. However, different iterations of GT and various forms of AR may inform the level of mutual compatibility. The goal of this conceptual paper is to answer two questions: Which iteration of GT could be more compatible with which form of AR? What benefits and challenges would such a methodological combination pose? The author presents a brief comparative review of GT and AR approaches, commenting on the intriguing complementarities of these methodologies and the benefits of their triangulation in social research. The author concludes that although the prospect of combining GT and AR is promising, it undeniably requires further scrutiny in applied research. This article will be helpful to graduate students and novice researchers who use AR methods and want to learn how GT compliments AR or can be used in conjunction with AR. It may also be useful to instructors who discuss AR methods in their course of study.
\end{abstract}

KeY WoRDS: Constructivist grounded theory; Participant engagement; Participatory action research; Qualitative inquiry; Triangulation

\section{INTRODUCTION}

Grounded Theory (GT) and Action Research (AR) methodologies are widely used in qualitative research. In fact, GT and AR, as well as mixed-methods research, have been found to be the three most common methodological approaches in qualitative research (Lingard, Albert, \& Levinson, 2008). Although GT and AR have some certain commonalities, they each offer multiple iterations and forms, which vary in their epistemological and methodological underpinnings. A researcher's knowledge of the specific versions of GT and $\mathrm{AR}$ and their mutual compatibility is important for the successful combined use of GT and $\mathrm{AR}$ in research. The purpose of this conceptual paper is to explore the benefits and 
challenges of the combined use of GT and AR in social research. Specifically, this paper aims to answer the following questions: Which iteration of GT could be more compatible with which form of AR? What benefits and challenges would such a methodological combination pose? This article will be helpful to graduate students and novice researchers who use AR methods and want to learn how GT compliments AR or can be used in conjunction with AR. It may also be useful to instructors who discuss AR methods in their course of study.

Combining GT and AR together in one study as complementary methodologies is what Azulai and Rankin (2012) describe as methodological triangulation, that is, "a combination of at least two or more data sources, methodological approaches, data analysis procedures or investigators to collect and analyze the data... Triangulation is typically used with the intention of strengthening the research design by counterbalancing the deficiency of any single strategy" (p. 125). Methodological triangulation in qualitative research can also enhance the rigor of a qualitative study by enhancing its trustworthiness: credibility, transferability, dependability, and confirmability elements of a research study (Lincoln \& Guba, 1985).

Triangulating GT or AR with other research methods is not a new notion. For instance, Wilson and Hutchinson (1991) and Annells (2006) discuss triangulating hermeneutical phenomenology and GT to enhance the rigor of data analyses. Further, Salas and Tillman (1998) discuss concurrent use of various AR approaches (e.g., Participatory Action Research and Participatory Rural Appraisal) in one study.

However, empirical studies that combine GT and AR are limited. Moreover, the rationale behind triangulating GT and AR is rarely described, and a discussion on the compatibility between GT and AR various forms is often missing. One example is provided by Teram, Schachter, and Stalker (2005), who use both methodologies in their research on health care in Canada. Specifically, the authors utilize GT and a form of AR, Participatory Action Research (PAR), to explore the experiences of women survivors of childhood sexual abuse who have received physical therapy $(N=27)$. As an outcome, Teram et al. hoped to develop a handbook for clinicians, sensitive to the needs and perspectives of those clients. The authors first employ GT during the data collection and analysis and share their interpretations of the data with participants for feedback. Next, Teram et al. use PAR to engage participants in drafting practice suggestions and guidelines for clinicians in monthly meetings during a period of six months. The information from these meetings results in a handbook on sensitive practice for clinicians. The authors conclude that the integration of GT and PAR was helpful in empowering clients to inform healthcare. Importantly, though, Teram et al. do not explicitly state what type of GT they used. From the cited references, it is possible to imply that they have used either traditional GT or Straussian GT (discussed later in this paper). However, these two iterations of GT have significant methodological differences. Also, using either of these GT iterations would have resulted in ontological and epistemological tensions with the AR methodology, particularly PAR, which Teram et al. do not address. These tensions will be discussed later in this paper. 
Another example is a study by Butterfield (2009), who uses GT and AR in a study of attainment and enjoyment of reading among primary school students $(N=173)$ in Jersey, UK, and reported that the combined use of GT and AR presented an effective approach to raise individuals' awareness across the school, and would have the potential to affect whole school functioning if used as a long-term process. Butterfield indicates using a constructivist version of GT through a series of solution-focused interviews, direct observation, and teacher assessments of reading within the school, inviting participant feedback. However, it is not clear from the paper which type of AR is used in the study.

Manuell and Graham (2017) present a conceptual paper, adopting GT, PAR, and Process Consultation to conceptualize new models to ease the processing and reporting of data in the disciplines of management and organizational behavior. The authors conclude that the new models added to the resources already available to early career investigators and graduate students. Manuell and Graham mention that their work is underpinned by the constructivist paradigm, which suggests that they have probably used a constructivist iteration of GT (discussed later in this paper). However, the authors do not examine the compatibility between the specific versions of GT and AR.

In another conceptual paper, Dick (2007) discusses the prospects of integrating GT and AR. Dick's intriguing discussion on the prospect of using GT and AR together in research to complement each other has informed this paper. However, more attention is needed to investigate the important epistemological and ontological tensions between these two approaches, as well as the methodological differences and (in)compatibilities between their different forms.

As Rieger (2019) points out, "[t]o rationalize the selection of a research methodology, one must understand its philosophical origins and unique characteristics" (p. 1). As qualitative researchers continue using various iterations of GT and forms of AR, sometimes combining both methodologies to complement each other, more detailed attention should be given to the potential compatibility between the different GT iterations and forms of AR. The current paper attempts to fill this gap. First, this article presents a brief overview of GT and AR methodologies. Next, a comparative analysis is provided of the perceived compatibilities and incompatibilities of GT and AR approaches in qualitative research, and the paper concludes with recommendations and further research directions.

\section{OVERVIEW OF GROUNDED THEORY}

Grounded theory has evolved over time. Today, it accommodates several versions or iterations, underpinned by diverse philosophical positions (Redman-MacLaren \& Mills, 2015). GT was originated by Glaser and Strauss in 1967 as an alternative approach to positivist doctrine on scientific research (Glaser \& Strauss, 2009). It offers a systematic and rigorous approach of inductive generation of theory, grounded in evidence (Glaser \& Strauss, 2009). It emphasises specific strategies and procedures for data collection and analysis, including theoretical sampling (i.e., sampling guided by emergent concepts); different levels of data coding through which categories develop (e.g., open coding, 
theoretical coding, selective coding); and the development of core categories of some basic social processes in the social phenomena under study (Cho \& Hanyang, 2014).

Since its inception, GT has evolved considerably to include several different iterations. The most notable versions include Traditional GT (also termed Classic or Glaserian), Straussian GT, and Constructivist GT. These different iterations share some core elements; however, they also differ significantly in their respective philosophical assumptions that guide the conception and the implementation of the research process (Rieger, 2019). The next sections provide an overview of the different iterations of GT including their main assumptions, characteristics, and the way each impacts the GT research process.

\section{Traditional GT (Also Called Classic or Glaserian GT)}

Glaser (2004) argues that the goal of the Traditional GT is to help develop new models or theories, grounded in data. Thus, for him, GT is both a research process and a product.

One of the main features of Traditional GT is a constant comparative method of data analysis, which occurs in a cyclic manner of ongoing comparison of data to data, data to categories, and categories to categories (Glaser \& Strauss, 2009). Another important feature of Traditional GT is the notion of theoretical sensitivity. Theoretical sensitivity refers to researchers being able to enter into a study bias-free, without pre-conceptions, to avoid forcing data into the analytical process (Glaser \& Strauss, 2009). One way to help develop theoretical sensitivity is the process of memo-writing, which involves a researcher making theoretical notes and conceptualizations of emerging categories while collecting and analysing data (Glaser, 2004).

To further develop theoretical sensitivity, GT researchers are urged to refrain from reading scholarly research literature up until the advanced stages of data analysis to minimize forming any pre-conceived notions about the study phenomenon (Glaser, 2004). Also, Glaser urges researchers to maintain distance from participants and use minimal questioning during the interview process to avoid the risk of forcing data. In Traditional GT, there is less concern about the accuracy of data in the representation of participants' voices; to Glaser, a theory is always an abstraction. Similarly, Glaser does not consider verification of an emergent grounded theory as important, for he believes that theorybuilding has a privilege of not being concerned with verifiability (Glaser, 2004).

Glaser believes that GT is a research methodology that can be successfully applied in both qualitative and quantitative studies, which epistemologically differentiates Traditional GT from later iterations (Glaser, 2004). To Glaser, any type of collected data (i.e., qualitative or quantitative) is valid for the purpose of the GT analysis (Glaser, 2007). Glaser suggests that the type of data is not as important as the adherence to the GT methodological procedures to ensure the emergence of a theory grounded in data (Glaser, 2007).

\section{Further Iterations of GT}

Later developments in GT by Strauss and Corbin $(1998,2008)$ offer some new and detailed technical procedures with a stronger emphasis on contextual influences, social conditions, 
and meaning in human behavior. Straussian GT introduces a refined coding system (with added axial coding) and the conditional matrix to trace the path of connectivity of repeated patterns and micro and macro conditions (Mills et al., 2006). Contrary to the Traditional GT by Glaser, Strauss and Corbin (1998) believe that reading literature before data analysis should not be prohibited, but rather encouraged, as it is believed to produce deeper awareness of sensitizing concepts. Given these unresolved disagreements between the two GT approaches, the treatment of literature is left to researchers' discretion in each given study (Cutcliffe, 2000).

Heath and Cowley (2004) suggest that the main source of divergence between Glaserian and Straussian versions of GT has been in epistemological and methodological, rather than ontological, aspects. Glaser's foundation in modernist research and Strauss's roots in symbolic interactionism with an emphasis on meaning, process and action have guided their different interpretations of GT, manifested in procedural variations (Clarke, 2003; Heath \& Cowley, 2004).

Further evolution of GT has led to its recent constructivist reconceptualization (Charmaz, 2014). In contrast to Traditional GT, constructivist grounded theorists focus on process and meaning, rather than process and product (Charmaz, 2000). For them, a theory is not emergent and knowledge is not discovered; rather, knowledge and theory are constructed through social interaction. According to Charmaz (2005), the constructivist approach to GT necessitates relationships with research participants, which requires less formal and longer interviews with participants. The emphasis is on searching for meaning, and on questioning the values and beliefs of both the participants and researcher. Charmaz (2000) suggests that these new procedures foster an interactive subjective experience within the contextual social conditions.

Importantly, Charmaz (2005) opposes the notion within Traditional GT that suggests a researcher should maintain a position of a distant expert. In the constructivist version, the researcher is a co-producer of experience: "What the viewer sees shapes what he or she will define, measure and analyse" (Charmaz, 2000, p. 524). As no analysis is considered neutral in Constructivist GT, taking a reflective stance on the researcher's existing assumptions and biases is a required part of the research process. To balance the representations of the researcher's and the participants' voices, Charmaz (2005) advocates maintaining participants' presence throughout the process of data analysis via full description of data in a literary form of writing; citing raw data to ensure data accuracy; and naming action codes and categories as close to the original wordings as possible. It is important, therefore, to embed the narrative of participants in the final research outcome (Charmaz, 2000).

In response to this perspective, Glaser (2004) suggests that preserving complex descriptions may distort analytical focus, generate confusion, and block abstracting of a theory. Also, Glaser (2002) is not convinced that acknowledging the researcher's biases is enough to produce quality grounded theory research. He believes that it is more important to use a rigorous constant comparison method to ensure the generation of grounded 
theory. Glaser disregards the term 'Constructivist GT' altogether, arguing that Constructivist GT is a form of Qualitative Data Analysis (QDA) (Glaser, 2004).

Theoretical discussions between the leading GT scholars continue along methodological and epistemological domains. For instance, Charmaz $(2000,2005)$ overtly states that her goal is to take GT away from its traditional objectivist-positivist origin. Although Charmaz (2014) acknowledges Glaser's genius in the conception and development of GT as a remarkable achievement in scientific research, she views Glaser as a positivist, given his quest for objective truth as well as his belief in an objective reality and neutrality of the researcher in the study process.

However, at the time of its conception, Traditional GT was a historically ground-breaking methodological innovation, driven by a rebellion against the mainstream positivist approach to research. Together with Strauss, Glaser broke through the positivist conception of scientific research by introducing researchers' reflections in the way of memoing (however restricted), flexibility in treating various sources of data, an evolving research design; and by disputing concerns about the generalizability of findings. Thus, firmly locating Glaser in a positivist camp would be, perhaps, not entirely accurate.

Furthermore, Charmaz (2005) situates Strauss and Corbin in the same positivist camp with Glaser, as they "advanced positivist procedures although different ones. They introduced new technical procedures and made verification an explicit goal, thus bringing GT closer to positivist ideas" (p. 508). Other scholars, however, suggest that the prescribing tone and the attention to technical details were Strauss's attempt to offer guidance to students and novice researchers in response to their ongoing struggles with the complexity of GT and their demands for concrete directions on how to conduct GT research (Weiner, 2007).

Importantly, Strauss and Corbin (1994) described their epistemological assumptions as being inconsistent with the positivist worldview, stating that they do not believe in a "preexisting reality 'out there.' To think otherwise is to take a positivistic position that... we reject... Our position is that truth is enacted" (p. 279). Strauss and Corbin also assert that GT is an "interpretive work and... interpretations must include the perspectives and voice of the people who we study [sic]" (Strauss \& Corbin, 1994, p. 279). Mills, Bonner and Francis (2006) address the individual evolution of Glaser's and Straus and Corbin's approaches to GT, illustrating the theorists' ongoing struggles to resolve questionable methodological, epistemological, and ontological issues. They state:

The literature... contains different opinions about the ontological nature of Strauss and Corbin... However, they did write an insightful book chapter that discusses the relationship of theory to reality and truth. This positions them as relativist pragmatists... stating that "theories are embedded in history" (Strauss \& Corbin, 1994, p. 280). Their work demonstrates a mixture of language that vacillates between positivism and constructivism (reliance on terms as "recognizing bias" and "maintaining objectivity"). But they accepted that it is not possible to be completely free of bias, acknowledged multiplicity of 
perspectives, and truths, and have extended and emphasized the range of theoretically sensitizing concepts." (p. 27)

Table 1 offers a summary of the main differences between the different iterations of GT based on the literature cited throughout, and specifically adapted from Charmaz (2017) and Riegar (2019). Although a clear consensus on the approach to GT has not been reached so far (Cutcliffe, 2000), some scholars suggest that the epistemological perspectives of researchers and their specific research questions are the key factors in selecting an appropriate approach for GT (Cutcliffe, 2000; Seale, 1999). Also, to borrow from Mills et al. (2006):

Grounded theory can be seen as a methodological spiral that begins with Glaser and Strauss' original text and continues today. The variety of epistemological positions that grounded theorists adopt are located at various points on this spiral and are reflective of their underlying ontology. (p. 1)

\section{OVERVIEW OF ACTION RESEARCH}

Action Research (AR) has emerged as an alternative to the more traditional positivistic view of social science (Chandler \& Torbert, 2003). Originated by Kurt Lewin in the 1940s, AR has been an applied approach to inquiry that is essentially participative and practicebased (Reason \& Bradbury, 2001). Lincoln (1998) states that action researchers strive to democratize knowledge as resistance to societal stratification along the lines of access to knowledge, unequal power relations, and oppression of marginalized groups. Mainstream research methods can be oppressive in that participants are used for information without necessarily benefiting from the findings (Reason, 1994). AR objects a positivistic approach to studies on participants, goes beyond the mainstream qualitative inquiry about participants, and rather, suggests conducting research with participants in respect-based partnerships and collaboration (Heron \& Reason, 1997). AR is an applied approach to research, often used to directly improve practice, to change organizational culture, and to empower marginalized groups and let their voices be heard.

A great variety of closely related forms of AR has been developed over time. This includes Participatory Action Research, Participatory Rural Appraisal, Co-Operative Inquiry, Action Inquiry, Emancipatory Action Research, Feminist Inquiry, Appreciative Inquiry, Fourth Generation Evaluation, Empowerment Evaluation, Action Learning, and Whole Systems, to name a few (Heron \& Reason, 1997; Pyrch, 1998; Reason \& Bradbury, 2001). All these forms of AR emphasise fostering research that is collective, cooperative, and interdisciplinary, and that aims to create a holistic, action-oriented inquiry (Pyrch, 1998). The differences between these various forms of AR are often subtle and organized around the extent of participants' involvement in various steps of the research process, as well as the power of a political message, the role of a researcher, and levels of critical appraisal. 
Table 1. Grounded Theory Iterations

\begin{tabular}{|c|c|c|c|}
\hline Category & $\begin{array}{l}\text { Traditional } \\
\text { Glaserian }\end{array}$ & Straussian & Constructivist \\
\hline $\begin{array}{l}\text { Ontological and } \\
\text { Epistemological } \\
\text { Assumptions }\end{array}$ & $\begin{array}{l}\text {-Arguably located on a continuum } \\
\text { between Positivist/ Post-positivist/ } \\
\text { Realist } \\
\text { - Objective reality/ truth/ knowledge } \\
\text { exists and can be discovered }\end{array}$ & $\begin{array}{l}\text { - Self-defined as Realist-Pragmatist } \\
\text { - Rooted in Symbolic-Interactionism } \\
\text { - Located on the continuum between } \\
\text { Post-Positivist/ Constructivist } \\
\text { - External reality exists, but people } \\
\text { subjectively interpret it } \\
\text { - Some knowledge can be discovered } \\
\text { but is never complete }\end{array}$ & $\begin{array}{l}\text { - Social Constructivism } \\
\text { - Relativism } \\
\text { - Subjectivism } \\
\text { - Multiple subjective realities exist } \\
\text { - Knowledge is socially constructed } \\
\text { - There is no one way to know }\end{array}$ \\
\hline Role of Researcher & $\begin{array}{l}\text { - Neutral expert observer } \\
\text { - Unbiased, objective, without pre- } \\
\text { conceived assumptions } \\
\text { - Distance from participants is valued } \\
\text { to allow theoretical abstraction }\end{array}$ & $\begin{array}{l}\text { - Neutral expert observer } \\
\text { - Researcher has an interpretive role }\end{array}$ & $\begin{array}{l}\text { - Objectivity is not possible / } \\
\text { researcher is biased } \\
\text { - Self-reflection is necessary } \\
\text { - Researcher co-creates knowledge } \\
\text { - Researcher documents close } \\
\text { descriptions of data to avoid forcing } \\
\text { personal assumptions into data }\end{array}$ \\
\hline $\begin{array}{l}\text { Role of Research } \\
\text { Participants }\end{array}$ & $\begin{array}{l}\text { - Informant/contributor } \\
\text { - Participants are not involved in the } \\
\text { research process aside from } \\
\text { contributing data }\end{array}$ & $\begin{array}{l}\text { - Informant/contributor } \\
\text { - Participants are not involved in the } \\
\text { research process aside from } \\
\text { contributing data }\end{array}$ & $\begin{array}{l}\text { - Participants co-create knowledge } \\
\text { - Relationships with participants are } \\
\text { important } \\
\text { - Participants contribute data and } \\
\text { member-check researcher's } \\
\text { interpretations }\end{array}$ \\
\hline $\begin{array}{l}\text { Context of Study } \\
\text { Phenomena }\end{array}$ & - Context of data is not considered & $\begin{array}{l}\text { - Context of data is considered using } \\
\text { conceptual/conditional matrix }\end{array}$ & - Context of data is always considered \\
\hline $\begin{array}{l}\text { Treatment of } \\
\text { Literature }\end{array}$ & $\begin{array}{l}\text { - Review of the literature is delayed, } \\
\text { preventing developing pre-conceived } \\
\text { ideas (and to help develop theoretical } \\
\text { sensitivity) } \\
\text {-Research questions are formed after } \\
\text { research begins }\end{array}$ & $\begin{array}{l}\text { - Review of literature can inform } \\
\text { research questions and, in fact, } \\
\text { increases theoretical sensitivity } \\
\text { - Research questions can be conceived } \\
\text { before research begins }\end{array}$ & $\begin{array}{l}\text { - Review of literature can help } \\
\text { develop theoretical sensitivity and } \\
\text { more accurate understanding of a } \\
\text { research topic } \\
\text { - Research questions are formulated } \\
\text { before research begins }\end{array}$ \\
\hline $\begin{array}{l}\text { Flexibility of } \\
\text { Methodological } \\
\text { Procedures }\end{array}$ & $\begin{array}{l}\text { - Unstructured interviews } \\
\text { - Both qualitative and quantitative } \\
\text { data can be used } \\
\text { - Directive, rigid, rigorous, systematic }\end{array}$ & $\begin{array}{l}\text { - Unstructured qualitative interviews } \\
\text { - Detailed, rigid, prescriptive system } \\
\text { of analytical tools } \\
\text { - The concept of 'smorgasbord' is used }\end{array}$ & $\begin{array}{l}\text { - Simplified, flexible data analysis } \\
\text { - Variations tolerated } \\
\text { - Unstructured or structured } \\
\text { qualitative interviews; interview }\end{array}$ \\
\hline
\end{tabular}


methodological process where modifications are considered harmful

to analytic quality

\section{Grounded Theory} as a Product category / major theme, leading to abstracting of a new theory to explain study phenomena

- Theory is a set of well-developed categories or themes, systematically inter-related to explain phenomena true explanation of study phenomena

$\begin{array}{ll}\text { Strengths } & \text { - Revolutionary thinking in a post- } \\ \text { positivist era that helped legitimize } \\ \text { qualitative research } \\ \text { - Rigorous methodology with more } \\ \text { flexible procedures than Straussian } \\ \text { GT } \\ \text { - High level of abstraction is often } \\ \text { achieved }\end{array}$

\section{Limitations} - Theory emerges from data and is a abstracting of a new theory to explain

\section{- Rigid, prescriptive, detailed} philosophical assumptions

- Lacks researcher self-reflection - Overstates researcher objectivity

- Privileges researcher knowledge by valuing distance from participants -Unchecked power differentials may result in forcing researcher's assumptions into data interpretation - Ignoring context of data by Strauss to imply a buffet-style of analytical tools

- The goal is to discover a core category / major theme, leading to study phenomena

- Theory is a set of well-developed categories or themes, systematically inter-related to explain phenomena - Theory emerges from data but represents only one plausible interpretation of reality

- Offers a clear description of the complex methodological procedures - Focuses on both micro and macro conditions, using developed conceptual/conditional matrix technique

- Rigorous analytical tools (coding paradigm) enable construction of an analytically sound theory methodological procedures

- Focus on detailed procedures may interfere with researcher's sensitivity

guides may be used

- The goal is to achieve abstract theorizing of relationships between concepts

- Theory does not emerge from the data and is not discovered; it is constructed;

- Theory is a constructed image of reality (one of many)

- Emphasizes participant-researcher relationships and attention to context - Researcher's self-reflection and provision of close descriptions of participant data helps limit risk of forcing data through researcher's interpretations

- Less prescriptive / complex methodological procedures - Strengthened methodological selfconsciousness

- May have less analytical power due to the simplified and less systematic methodological procedures - Simplification results in a resemblance with common Qualitative Data Analysis

- Power differential between researcher and participants is not addressed - Creating interview guides may introduce researcher bias and force data 
Participation is a key feature of AR. According to Greenwood and Levin (1998), AR is an inquiry where participants and researchers co-create knowledge through collaboration (Dugan, 1996). The degree of participation in different forms of AR varies, ranging from the active engagement of participants in data collection to full participation in all stages of a research project.

Methodologically, AR has a repeated five-stage cycle that includes: (1) problematizing: identifying and area for improvement; (2) planning: designing an innovative plan to help create the identified improvement; (3) action: implementing the plan for the identified innovative practice in the real life; (4) observing: systematically collecting research data on the intervention; and (5) reflecting: reviewing, exploring, and reflecting on the findings to evaluate the effectiveness of the intervention in improving the identified area in the problematizing stage (Kemmis \& McTaggart, 2000; Manuall \& Graham, 2017).

Within this cycle, AR unfolds as a spiral movement back and forth between the action and the critical reflection stages: research facilitates action, which in turn facilitates research (Dick, 2007). According to Dick (2007), critical reflection stimulates the emergence of theory through developing an understanding of what is happening, and how. This understanding helps in planning new actions and testing them immediately. It is important to note, though, that the flow from stage to stage in the AR cycle is not always linear; in fact, sometimes the stages overlap. Reflection on the action can prompt additional data collection and action, etc. As AR is implemented in real life situations and aims to impact real-life problems, the context often requires flexible and dynamic design (Kemmis \& McTaggart, 2000).

According to Kemmis and McTaggart (2000), AR usually involves interviews, field observations, participant reflections, audiotaped planning meetings, etc., but might also require a carefully designed survey or critical analyses of documents. In fact, there is no restriction in AR on the type of data - qualitative or quantitative. Rather, any data can be collected to answer the research question at hand. Thus, it is quite possible to triangulate several methodologies in a project over a series of AR cycles.

AR postulates that theory and action should not be separated, although experience is generally emphasised over an abstract role of theorizing (MacLure, 1995). Levin and Greenwood (2001, p. 105) outline the following principles of AR:

- $\quad$ AR is context-bound and addresses real life problems.

- In AR, participants and researchers collaboratively co-create knowledge.

- AR treats the diversity of experience and capacities within participants as an opportunity for the enrichment of the research process.

- The AR inquiry process leads to social action or the collective reflections on social action lead to the construction of new meanings.

- The credibility/validity of AR knowledge is measured according to whether actions that arise from it solve real life problems and increase participants' control over their own situation. 
Greenwood and Levin (1998) regard AR as a warrant for action owing to its hands-on orientation to solving pressing problems (Greenwood \& Levin, 1998; Manuell \& Graham, 2017). Detailed attention to cases, context, and history is essential. Also, a respectful approach to diversity within situations is necessary, as well as developing an understanding of what happened in each case. As Greenwood and Levin (1998) state:

AR rejects both unquestioned authority and realism/positivism as reasonable approaches to social learning and social change. Unlike local activism, it also rejects pure relativism and an uncritical commitment to the group it serves. It is a form of discussion, of critical communication that generates new and often painful knowledge. AR processes create an arena in which the forces of authority and community, realism and relativism, meet in communicative situations that are structured to open up all positions for scrutiny as well as for positive contributions. And AR is open to all and aims to keep the conversation going. (p. 258)

However, some paradigmatic tension in the AR family is noteworthy. Kemmis (2001) locates AR within the paradigm of critical theory. Reason and Bradbury (2001) situate AR in participatory and ecological paradigms. Despite these tensions, a core concept in AR is a personal and professional sense of social efficacy which derives from enabling others to achieve power or empower themselves (Lincoln, 1998).

Miller and Campbell (2006) suggest that at the level of an individual, psychologically empowering processes are those that provide opportunities for people to work with others, learn decision-making skills, and manage resources. Empowering processes include shared responsibility, leadership, and opportunities to participate in decision-making, all of which underpin the AR research process with participants (Miller \& Campbell, 2006). The question is, how are these processes compatible with GT methodology? Below, I discuss the points of connection between GT and AR as well as the points of the tension between them, which may impact the methodological triangulation of these approaches in research.

\section{WHERE Do GT AND AR CONNECT?}

Although GT and AR are not usually perceived as similar methodologies, they have some features in common, including the spiral or cyclic process of data collection and analysis, a commitment to theory generation that is grounded in practice-based evidence, and an emphasis on contextual conditions in studying social phenomena (Dick, 2007).

From a methodological standpoint, both GT and AR involve cyclic processes in the data analyses as well as similar coding procedures (Dick, 2007). Huxham and Vangen (2003) offer a methodological description of AR procedures that includes: identification of data relevant to the purpose of a study; collaborative efforts with colleagues to agree upon the items to include (similar to reflecting and memo-writing in GT) and how to cluster these items (similar to the creation of codes and categories in GT); labeling the clusters (similar to naming categories in GT); creating a conceptual framework from the clusters (similar to 
creating a core category in GT); reviewing data from other studies and refining the framework (similar to the treatment of literature in GT), and seeking feedback from participants involved in the study (similar to the member-check technique in GT). Manuell and Graham (2017), who apply GT in AR in a study on organizational behavior, suggest that the GT data collection process shadows that of AR and supports it with its fact-finding and recording of the data. Specifically, the constant comparison method in GT, where a researcher must make constant comparisons between data with what is already known elsewhere, parallels the stages within the repeating cycle of AR - planning, acting, observing, and reflecting.

Further, both GT and AR share commitment to developing theoretical understanding, grounded in practice-based evidence, which results in a concrete outcome (Charmaz, 2005; Dick, 2007). In GT, a theory is both a process and a product of research (Charmaz, 2005), while in AR gaining theoretical understanding grounded in praxis facilitates actively achieving social change (Dick, 2007).

Finally, both AR and GT pay special attention to the contextual conditions of social phenomena. This is especially prominent in participatory types of AR and the constructivist iteration of GT. Charmaz (2005), for instance, openly acknowledges the similarity between the Constructivist GT and Participatory Action Research (PAR) in their attention to social justice as a research goal and a process. She highlights the notion of democratic participation in research and the importance of engagement of participants in research, equal opportunity for all participants to share their views, avoiding abuse of power in research and making sure that participants benefit from the findings. This resembles the AR principle of doing research with participants, rather than on or about them.

\section{WHERE DO GT AND AR DIVERGE?}

Despite the similarities, there are several diverging aspects in GT and AR that researchers need to remember when one considers combining the two methodologies in one study. These include the following: 1) engagement in action versus theorizing; 2) the role of the researcher as an expert versus co-participant; 3) degree of participant involvement in various stages of research; and 4) rigor of data analyses. These differences are discussed below.

\section{Engagement in Action versus Theorizing}

GT is explicit about how to develop theory. Although Dick (2007) regards both GT and AR as 'emergent methodologies,' this term is not without controversy. As mentioned earlier, although theory may be perceived as emerging in Traditional GT (Glaser, 2002), it is deemed socially constructed in Charmaz's conceptualization (2005). In AR, theorizing remains, probably, the most challenging aspect of AR (Dick, 2007). This is because AR emphasizes experience over theory, even though theorizing is deemed important (Dick, 2007). 


\section{The Role of the Researcher: An Expert or a Co-Participant?}

In $A R$, a researcher is not an expert but a co-participant in the process of co-creation of knowledge (Pyrch, 1998). At the same time, participants are co-researchers as they share insights into their own life experiences, which they know better than researchers. This power-sharing in the research process is an important principle in AR for its empowering and transformational capacities as researchers and participants own the research process together.

In contrast, a GT researcher is perceived to be an expert, tasked with building a theory, whereas participants are informants only (Dick, 2007). The concept of abduction that is used in theory creation can mediate distancing. Abduction refers to the ability of a researcher to move back and forth between experiencing, reflecting, and theorizing to notice new patterns. Both inductive and deductive thinking are utilized here, which requires some distancing from participants, necessary to abstract a theory. In GT (regardless of the iteration), the ultimate control over the research process and the outcomes are in the hands of the researcher.

\section{Degree of Participant Involvement in Research}

In AR, the involvement of participants, at least to some extent, is obligatory as it facilitates democratic and emancipatory inquiry (Pyrch, 1998). The most participatory forms of AR (e.g., PAR or Co-operative Inquiry) engage participants in every aspect of the research process, including the formulation of research questions, research design, data collection, and data analysis (Dick, 2007).

In GT, however, the involvement of participants in research is an unresolved dilemma. Charmaz (2005), though generally supportive of an experiential reengagement with participants in research, argues that researchers need to weigh when, how, and to what extent to bring participants into the process as it might create a series of challenges. For example, involving participants in data analysis poses a risk of unintentional harm to the participants by invading their privacy or by breaking confidentiality (Goldblatt et al., 2011). This can be particularly problematic in the research of human services organizations, where confidentiality between the workers and their clients is strictly enforced.

Another argument against the full involvement of participants in the research process relates to the issue of suspected exploitation of participants' work without pay or recognition (Morse, 1998). Of course, monetary payment is not the only way of compensation. Such empowering benefits as actively participating in problem-solving, fostering change in participants' life situations, participating in knowledge transfer, and being valued and acknowledged as experts of their own lives should not be underestimated.

Still another argument against full involvement of participants in research is a concern that participants might veto theorizing of the researcher (Morse, 1998). Dick (2007) suggests, however, that it is not a potential risk because if a researcher and participants are regarded as equals in the research endeavor, "they can reconcile their differences. In this process of 
mutual education, each of them will find their understanding deepened" (p. 406). On the other hand, not allowing interested participants to engage in all aspects of the research process may raise issues related to research ethics. Moreover, it may be particularly problematic in a research project that proposes using GT together with AR, where participants are perceived as experts and are encouraged to participate as fully as possible in a research process.

\section{Rigor of Data Analysis}

Some scholars have expressed methodological concerns about AR (Goldblatt et al., 2011). Despite the emphasis on praxis and practice-based evidence, AR has been criticized as 'unscientific' and as a marginal methodology by mainstream research, which claims AR has vague methodological procedures. For instance, since AR is built on the notion of contextbound inquiry, transferability of knowledge from one location to another is not achieved by abstract generalizations about that knowledge (Greenwood \& Levin, 1998). Some scholars suggest that this is because AR ascribes higher priority to obtaining useful evidence over methodological rigor:

In most action research, including participatory action research, the researchers make sacrifices in methodological and technical rigor in exchange for more immediate gains in face validity: whether the evidence they collect makes sense to them, in their contexts. For this reason, we sometimes characterize participatory action research as "low tech" research: It sacrifices methodological sophistication in order to generate timely evidence that can be used and further developed in a real-time process of transformation... (Kemmis \& McTaggart, 2000, p. 591)

Morse (1998) states that bringing participants into research decisions means risking reducing the quality of data analysis because participants may not have proper research training. However, the notion that sharing ownership over the research process with participants decreases rigor of research may sound presumptuous. By sharing power and expertise with the participants, the AR researcher is not excused from performing rigorous data collection and analysis and to guide and train participants. While sharing power and knowledge in data analysis, the researcher's assumptions (as well as those of the participants) get scrutinized, which helps to control existing assumptions and biases, thereby increasing credibility, dependability, confirmability and the overall trustworthiness of the study (Sikolia et al., 2013). It is a researcher's responsibility to keep a balanced representation of their own and participants' voices in the study.

Greenwood \& Levin (1998) argue that marginalization of AR is not due to its limited scientific rigor but rather because it promotes different ways of knowing, thereby challenging the status quo of mainstream research:

Pushing AR to the margins of the scientific research is a result of not so much a weakness of AR as scientific inquiry, but in the general lack of commitment to 
democratic social change in our societies... [as well as in a] "threat of co-optation" inherent in AR that the mainstream strive to leave open. (p. 259)

What complicates the matter, though, is that AR studies rarely offer a clear description of methodological procedures, which has not been helpful in adding clarity about AR methodological procedures in action. Some researchers have attempted to bring clarity by triangulating AR with other research approaches, including GT, to strengthen the methodological procedures while maintaining the action-oriented, empowerment-driven research process. As Dick (2007) commented, “action research literature didn't explain how to analyze data: grounded theory literature did" (p. 402); therefore "action research is often viewed... mistakenly... as lacking rigor," whereas "grounded theory analysis is often included within an action research studies... to provide rigor" (p. 403).

From the evaluation perspective of research rigor, GT is judged by whether the emergent (or constructed) theory about the studied phenomenon is pertinent, workable, useful, modifiable, original, credible, and resonating (Charmaz, 2005; Glaser \& Strauss, 2009; Sikolia et al., 2013). AR is judged according to whether actions (however defined) that arise from a research project solve real-life problems and increase participants' control over their situations (Lincoln, 1998).

\section{Considerations for Methodological Triangulation of GT AND AR}

Strauss and Corbin use the term smorgasbord as a metaphor to draw a parallel between GT and a buffet-style table from which GT researchers can pick and choose (Mills et al., 2006). This metaphor seems to encourage experimentation within GT, which can be applied to combining GT and AR approaches to complement and strengthen each other.

Dick (2007) theorized what GT and AR can learn from each other. AR can learn from grounded theorists "by being more explicit about the actual theory they develop and the ways to do so," while "grounded theorists can learn from action researchers how to engage participants in the research process and how to include in research action pieces to foster social change if they wish" (Dick, 2007, p. 399). According to Dick (2007), the methodical, explicit, and systematic data generation and analysis, practiced in GT, supports and enhances AR. On the other hand, the inclusive approach in AR, where participants engage as co-researchers, allows for the enriching exchange of the technical knowledge of a researcher and the insider knowledge of participants, thereby generating a fuller understanding of a studied phenomenon. Dick (2007) continues that "grounded theorists and action researchers can expand their repertoire and their relevance to practice and theory by borrowing each other's methods, techniques and skills" (p. 411). He provides an example of "grounded action research" in the information systems literature, featuring GT inserted into AR cycles with the intention to add rigor to the theory formulation process. In that example, while AR guides the intervention process, GT is used for data analyses and theory building. This combination was justified for that specific study because neither GT nor AR alone was enough to ensure the combination of methodological rigor and relationship development with participants. Abdel-Fattah (2015) supports the notion of 
the methodological superiority of GT over AR and suggests that GT has greater capacity for formalizing, interpreting and analyzing data (Abdel-Fattah, 2015).

Some scholars comment on the lengthy process of GT research, particularly the traditional and the Straussian iterations, due to the laborious coding, which slows down the process (Abdel-Fattah, 2015; Dick, 2007). The same issue exists with participatory forms of AR, where open deep sharing between researchers and participants may require considerable time to build relationships, rapport, and mutual trust (Pyrch, 1998). What happens when GT and AR are used together? Time is a significant resource required for this type of study; this should not be underestimated and is, perhaps, one of the biggest limitations of the combined approach (Butterfield, 2009).

\section{CONCLUDing Notes AND FutuRE DiRECTIONS}

Some scholars offer a pragmatic view on the triangulation of GT and AR, regardless of their respective iterations and forms; namely an approach that is "eclectic, borrowed from any version that suits" (Dick, 2007, p. 401). However, it may be worthwhile to consider the compatibility of the respective iterations of GT and AR in the research design to minimize methodological and epistemological tensions in the research process. For example, participatory forms of AR (such as Participatory Action Research, Participatory Rural Appraisal, Co-operative Inquiry, and Empowerment Evaluation) would, perhaps, find more connecting points with the constructivist iteration of GT owing to the mutual emphasis on reflexivity and democratic participation (however defined) of participants. Strauss's and Corbin's iterations of GT may also be useful in this case, given their emphasis on meaning, process, and action, reflexivity, attention to contexts and conditions of social phenomena, as well as developed questioning techniques. On the other hand, methodological principles of the Traditional GT can be useful in less participatory forms of AR (e.g., Action Learning, Action Inquiry and Appreciative Inquiry) on the condition that the use of Traditional GT is decontextualized from its anti-participatory and expertise-driven epistemological underpinnings (Dick, 2007).

The role of a researcher and participants and the degree of participants' involvement in the research process will, most likely, remain an ongoing point of tension between GT and AR, regardless of their respective iterations. "If the reality is deemed socially constructed (as it is in the constructivist GT, for instance), then greater participation of those who have experience of the phenomenon has the potential to increase the rigor of research results" (Redman-MacLaren \& Mills, 2015, p. 5). However, even in the constructivist iteration of GT, intensive involvement of participants in the research process has been viewed as potentially problematic (Charmaz, 2005).

The researcher's own ontological views and epistemological approach may enable (or, on the contrary, constrict) conditions for the combined use of GT and AR in one study. To reconcile this tension, Redman-MacLaren and Mills (2015) go a step further in GT development and conceptualize a Transformative GT, underpinned by the philosophy of critical realism, elements of Participatory Action Research, and decolonizing methodologies. Redman-MacLaren and Mills state that Transformational GT is founded on 
key grounded theory methods but adopts guidelines from PAR and decolonizing methodologies to enable action, generation of new knowledge, and equalizing of a power differential between researcher and participants, whom Transformative GT regards as coresearchers. The authors provide a rationale for expanding GT as a critical GT methodology that focuses on "privileging of participation, redistribution of power in research [between researcher and co-researchers] and promoting action for positive change" (RedmanMacLaren \& Mills, 2015, p. 2). The authors argue that this critical transformative version of GT would allow for both theory development and action. Although the creation of the transformative GT by bridging GT with PAR is very promising, it warrants further investigation in the field. In the same vein, triangulating any form of GT and AR requires further scrutiny through practical application. Borrowing from Strauss's view, such an application will be "judged by results" (Weiner, 2007, p. 309).

\section{REFERENCES}

Abdel-Fattah, M. A. (2015). Grounded theory and action research as pillars for interpretive information systems research: A comparative study. Egyptian Informatics journal, 16(3), 309-327. https://doi.org/10.1016/j.eij.2015.07.002

Annells, M. (2006). Triangulation of qualitative approaches: Hermeneutical phenomenology and grounded theory. Journal of Advanced Nursing, 56(1), 55-61. https://doi.org/10.1111/j.1365-2648.2006.03979.

Azulai, A., \& Rankin, J. (2012). Triangulation in Canadian doctoral dissertations on aging. International Journal of Multiple Research Approaches, 6(2), 125-140. https://doi.org/10.5172/mra.2012.6.2.125

Butterfield, J. (2009). Using grounded theory and action research to raise attainment in, and enjoyment of, reading. Educational Psychology in Practice, 25(4), 315-326. https://doi.org/10.1080/02667360903315131

Chandler, D., \& Torbert, B. (2003). Transforming inquiry and action: Interweaving 27 flavours of action research. Action Research, 1(2), 133-152. https://doi.org/10.1177/14767503030012002

Charmaz, K. (2000). Grounded theory: Objectivist and constructivist methods. In N. K Denzin \& Y. S. Lincoln (Eds.), Handbook of qualitative research (2 ${ }^{\text {nd }}$ ed.) (pp. 509 530). Sage Publications.

Charmaz, K. (2005). Grounded theory in the 21 $1^{\text {st }}$ century: Applications for advancing social justice studies. In N. K Denzin and Y. S. Lincoln (Eds.) Sage handbook of qualitative research ( $3^{\text {rd }}$ ed.) (pp. 507-535). Sage Publications.

Charmaz, K. (2014). Constructing grounded theory (2nd ed.). Sage Publications. 
Charmaz, K. (2017). Special invited paper: Continuities, contradictions, and critical inquiry in grounded theory. International Journal of Qualitative Methods, 6(11). https://doi.org/10.1177/1609406917719350

Cho, J. Y., \& Hanyang, E. L. (2014). Reducing confusion about grounded theory and qualitative content analysis: Similarities and differences. The Qualitative Report, 19(64), 1-20. http://www.nova.edu/ssss/QR/QR19/cho64.pdf

Clarke, A. (2003). Situational analyses: Grounded theory mapping after post-modern turn. Symbolic Interaction, 26(4), 553-576. https://doi.org/10.1525/si.2003.26.4.553

Cutcliffe, J. R. (2000). Methodological issues in grounded theory. Journal of Advanced Nursing, 31(6), 1476-1484. https://doi.org/10.1046/j.1365-2648.2000.01430.x

Dick, B. (2007). What can grounded theorists and action researchers learn from each other? In K. Charmaz and A. Bryant (Eds.), The Sage handbook of grounded theory (pp. 398416). Sage Publications, Inc.

Dugan, M. A. (1996). Participatory and empowerment evaluation: Lessons learned in training and teaching assistance. In D. M. Fetterman, S. J. Kafrarian \& A. Wandersman (Eds.), Empowerment evaluation: Knowledge and tools for selfassessment and accountability (pp. 277-304). Sage Publications.

Glaser, B. (2002). Constructivist grounded theory? Forum: Qualitative Social Research, 3(3). Retrieved April 8, 2010 from http://www.qualitative-research.net/fqs-texte/302/3-02glaser-e.htm

Glaser, B. (2004). Remodelling grounded theory. Forum: Qualitative Social Research, 5(2). https://www.qualitative-research.net/index.php/fqs/article/view/607/1316

Glaser, B. (2007). All is data. Grounded Theory Review, 2(6). http://groundedtheory review.com/wp-content/uploads/2012/06/GT-Review-vol6-no2.pdf

Glaser, B., \& Strauss, A. (2009). The discovery of grounded theory: Strategies for qualitative researchers. Aldine Transaction. (Original work published in 1967)

Goldblatt, H., Karnielli-Miller, O., \& Neumann, M. (2011). Sharing qualitative research findings with participants: Study experiences of methodological and ethical dilemmas. Patient Education and Counselling, 82(3), 389-395. https://doi.org/10.1016/j.pec.2010.12.016

Greenwood, D. J., \& Levin, M. (1998). Action research, science, and co-optation of social research. Studies in Cultures, Organizations and Societies, 4(2), 237-261. https://doi.org/10.1080/10245289808523514 
Heath, H., \& Cowley, S. (2004). Developing a grounded theory approach: A comparison of Glaser and Strauss. International Journal of Nursing Studies, 41(2), 141-150. https://doi.org/10.1016/S0020-7489(03)00113-5

Heron, J., \& Reason, P. (1997). A participatory inquiry paradigm. Qualitative Inquiry, 3(3), 274-294. https://doi.org/10.1177/107780049700300302

Huxham, C., \& Vangen, S. (2003). Researching organizational practice through action research: Case studies and design choices. Organizational Research Methods, 6(3), 383-403. https://doi.org/10.1177/1094428103254454.

Kemmis, S. (2001). Exploring the relevance of critical theory for action research: Emancipatory action research in the footsteps of Jürgen Haberamas. In P. Reason \& H. Bradbury (Eds.), Handbook of action research (pp. 91-102). Sage Publications.

Kemmis, S., \& McTaggart, R. (2000). Participatory action research. In N. K. Denzin \& Y. S Lincoln (Eds.), Handbook of qualitative research (2nd ed.) (pp. 567-605). Sage.

Levin, M., \& Greenwood, D. (2001). Pragmatic action research and the struggle to transform universities into learning communities. In P. Reason \& H. Bradbury (Eds.), Handbook of action research (pp. 103-113). Sage Publications.

Lincoln, Y. S. (1998). Commodification and contradiction in academic research. Studies in Cultures, Organizations, and Societies, 4(2), 263-278. https://doi.org/10.1080 /10245289808523515

Lincoln, Y. S., \& Guba, E. G. (1985). Naturalistic inquiry. Sage.

Lingard, L., Albert, M., \& Levinson, W. (2008). Grounded theory, mixed methods, and action research. BMJ, 337(a567). https://doi.org/10.1136/bmj.39602.690162.47

MacLure, M. (1995). Postmodernism: A postscript. In C. Day, J. Elliott, B. Somekh \& R. Winter (Eds.), Theory and practice in action research: Some international perpsectives (pp. 61-73). Symposium Books.

Manuell, P., \& Graham, W. (2017). Grounded theory: An action research perspective with models to help early career researchers. e-Journal of Social \& Behavioural Research in Business, 8(1), 74-90.

Miller, R. L., \& Campbell, R. (2006). Taking stock of empowerment evaluation: An empirical review. American Journal of Evaluation, 27(3), 296-319. https://doi.org/10.1177/1098214006291015 
Mills, J., Bonner, A., \& Francis, K. (2006). The development of constructivist grounded theory. International Journal of Qualitative Methods, 5(1), 25-35. https://doi.org/10.1177/160940690600500103

Morse, J. M. (1998). Validity by committee. Qualitative Health Research, 8(4), 443-445. https://doi.org/10.1177/104973239800800401

Pyrch, T. (1998). Introduction to the action research family. Studies in Cultures, Organizations and Societies, 4(2), v-x. https://doi.org/10.1080/102452 89808523508

Reason, P. (1994). Three approaches to participative inquiry. In N. K. Denzin \& Y. S. Lincoln (Eds.), Handbook of qualitative research (pp. 324-339). Sage.

Reason, P., \& Bradbury, H. (Eds.). (2001). Handbook of action research: Participative inquiry and practice. Sage Publications.

Redman-MacLaren, M., \& Mills. J. (2015). Transformational grounded theory: Theory, voice, and action. International Journal of Qualitative Methods, 14(3), 1-12. https://doi.org/10.1177/160940691501499301

Rieger, K. L. (2019). Discriminating between grounded theory approaches. Nursing Inquiry, 26(1), 1-12. https://doi.org/10.1111/nin.12261

Salas, M., \& Tillman, T. (1998). About people's dreams and visions and how to retune our perceptions: Convergence of PAR and PRA in Latin America. Studies in Culture, Organizations, and Societies, 4(2), 169-186. https://doi.org/10.1080 /10245289808523510

Seale, C. (1999). The quality of qualitative research. Sage Publications.

Sikolia, D., Biros, D., Mason, M., \& Weiser, M. (2013). Trustworthiness of grounded theory methodology research in information systems. MWAIS, Proceedings, 16. http://aisel.aisnet.org/mwais2013/16.

Strauss, A., \& Corbin, J. (1994). Grounded theory methodology: An overview. In N.K. Denzin and Y.S. Lincoln Y.S. (Eds.), Handbook of qualitative research. Sage Publications.

Strauss, A., \& Corbin, J. (1998). Basics of qualitative research: Techniques and procedures for developing grounded theory (2nd ed.). Sage Publications.

Strauss, A., \& Corbin, J. (2008). Basics of qualitative research: Techniques and procedures for developing grounded theory (3rd ed). Sage Publications. 
Teram, E., Schachter, C.L., \& Stalker, C. A. (2005). The case of integrating grounded theory and participatory action research: Empowering clients to inform professional practice. Qualitative Health Research, 15(X), 1-12. http://doi.org/10.1177 /1049732305275882

Weiner, C. (2007). Making teams work in conducting grounded theory. In K. Charmaz \& A. Bryant (Eds.), The Sage handbook of grounded theory. Sage Publications, Inc.

Wilson, H.S., \& Hutchinson, S.A. (1991). Triangulation of qualitative methods: Heideggerian hermeneutics and grounded theory. Qualitative Health Research, 1(2), 263-276. https://doi.org/10.1177/104973239100100206

\section{BIOGRAPHICAL NOTE:}

Anna Azulai is Assistant Professor in the School of Social Work, Faculty of Health and Community Studies at MacEwan University, Canada. Dr Azulai is a clinical social worker, educator, and researcher with interests in mental health, aging, and inter-professional collaboration. 